\title{
Formulation of mayonnaises containing PUFAs by the addition of microencapsulated chia seeds, pumpkin seeds and baru oils
}

\author{
Valquíria Maeda Rojas ${ }^{\mathrm{a}}$, Luis Felipe da Costa Baptista Marconi ${ }^{\mathrm{b}}$, Alexandre Guimarães-Inácio ${ }^{\mathrm{a}}$, \\ Fernanda Vitória Leimann ${ }^{\mathrm{a}, \mathrm{c}, \mathrm{d}}$, Augusto Tanamati ${ }^{\mathrm{b}}$, Ângela Maria Gozzo ${ }^{\mathrm{b}}$, \\ Renata Hernandez Barros Fuchs ${ }^{\mathrm{b}}$, Maria Filomena Barreiro ${ }^{\mathrm{c}, \mathrm{d}}$, Lillian Barros ${ }^{\mathrm{d}}$, \\ Isabel C.F.R. Ferreira ${ }^{\mathrm{d}, *}$, Ailey Aparecida Coelho Tanamati ${ }^{\mathrm{a}}$, Odinei Hess Gonçalves ${ }^{\mathrm{a}, \mathrm{c}, \mathrm{d}}$ \\ a Post-Graduation Program of Food Technology, Federal University of Technology - Paraná, Via Rosalina M. Santos, 1233, 87301-899, Campo Mourão, Paraná, Brazil
b Food Department, Federal University of Technology - Paraná, Via Rosalina M. Santos, 1233, CEP 87301-899, Campo Mourão, Paraná, Brazil
c Laboratory of Separation and Reaction Engineering - Laboratory of Catalysis and Materials (LSRE-LCM), Polytechnic Institute of Bragança, Campus Santa Apolónia,
$5301-857$ Bragança, Portugal
d Centro de Investigação de Montanha (CIMO), Instituto Politécnico de Bragança, Campus Santa Apolónia, 5300-253 Bragança, Portugal
}

\section{A R T I C L E I N F O}

\section{Keywords:}

Mayonnaise

Rheology

Mechanical texture

PUFAs

Microencapsulation

\begin{abstract}
A B S T R A C T
There is an increasing demand for healthier foodstuff containing specific compounds such as Polyunsaturated Fatty Acids (PUFAs). In the case of PUFAs, protection against oxidative degradation is challengeable and microencapsulation emerges as an alternative. Mayonnaises containing microencapsulated oils could be a source of PUFAs. The objective was to formulate mayonnaises containing microencapsulated chia seeds oil, pumpkin seeds oil or baru oil. Micrometric particles with high encapsulation efficiency were produced and thermal analyses indicated an increased thermal stability of all oils after encapsulation. Rheology studies highlighted an increase in the mayonnaise viscosity when microparticles containing chia and pumpkin seeds oil were added. Mechanical texture was not affected by the presence of microparticles in the mayonnaise in all formulations tested. Nevertheless, samples containing microcapsules up to 5\%wt were not distinguished from the base-mayonnaise in the sensorial test. Overall, enriched mayonnaises were successfully produced and encapsulation was efficient in protecting oils from oxidation.
\end{abstract}

\section{Introduction}

Mayonnaise is an oil-in-water emulsion stabilized by emulsifying agents present in the egg yolk and egg white (Rahmati, Tehrani, \& Daneshvar, 2014). It has a low-pH and a high lipid content (Di Mattia et al., 2015) and the base components are oil, water, egg yolk and vinegar. Mayonnaise is one of the most common emulsion-based foods and effort have been made to improve it nutritional value and to reduce its caloric content (Alvarez-Sabatel, Martínez de Marañón, \& Arboleya, 2018; Chivero, Gohtani, Yoshii, \& Nakamura, 2016). Partial substitution of fat is also reported in the literature using microparticulated whey protein (Sun et al., 2018). In all cases, texture and rheological behavior are important factors that could affect sensory perception, physical stability and consumer satisfaction (Di Mattia et al., 2015).

The growing number of health-oriented consumers is pressuring the food industry to develop healthier foodstuff or foods that containing functional components (Miele, Di Monaco, Cavella, \& Masi, 2010). The addition of oils containing polyunsaturated fatty acids (PUFAs) to staple, well-accepted foods like mayonnaise may be an alternative to improve the dietary intake of omega $3(n-3)$ and omega 6 (n-6). The contents of these fatty acids are associated with nutritional aspects and consumption of monounsaturated fatty acids is recommended to reduce cardiovascular risk (Wood et al., 2004). Recent findings showed that n6:n-3 ratio may affect the selectivity of the lipid cytotoxic activity towards normal or tumor cells (Mansara, Deshpande, Vaidya, \& KaulGhanekar, 2015). Also, it is reported that the imbalance of n-6 and n-3 in diet is closely related to metabolic disorders and chronic diseases (Simopoulos, 2008).

PUFAs are found in a variety of vegetable oils such as chia seeds oil, pumpkin seeds oil and baru oil. Chia (Salvia hispanica L.) seeds have high content of oil, proteins, antioxidants, and minerals. Its health reputation is mainly associated with a high content of unsaturated fatty

\footnotetext{
* Corresponding author.

E-mail address: iferreira@ipb.pt (I.C.F.R. Ferreira).
} 
acids (Timilsena, Vongsvivut, Adhikari, \& Adhikari, 2017). Pumpkin (Cucurbita maxima) seeds oil is an excellent source of antioxidants like polyphenols, tocopherols, carotenoids, and PUFAs, contributing to disease prevention and health promotion (Siano et al., 2016). Pumpkin seeds have an average lipids concentration of $35-45 \%$, and their fatty acids composition comprise oleic (23.9\%) and linoleic (53.3\%) acids (Jiao et al., 2014). Baru (Dipteryx alata) oil, obtained from barueiro chestnut, has excellent food parameters and high nutritional value and can be used in food, pharmaceuticals and cosmetics (Silva et al., 2015).

It is well known that oils rich in polyunsaturated fatty acids are susceptible to oxidation and degradation, which may decrease sensory quality. In addition, some oxidation products may be harmful to human health. The presence of oxygen, free fatty acids, mono and diacylglycerols, transition metals, pigments and thermally oxidized compounds directly influence the oxidative stability of oils (Ixtaina et al., 2011). Differential Scanning Calorimetry (DSC) is a remarkable tool to evaluate the oxidation of lipid materials due to the exothermic character of the lipid oxidation reaction. Also, DSC is a very fast analysis and requires only small amounts of sample when compared to conventional techniques like Rancimat tests. In addition, it has been demonstrated that results of Rancimat and DSC present high correlation degree (Ostrowska-Ligeza et al., 2010). DSC was used to evaluate the oxidative stability of toogga oil (Gardette \& Baba, 2013), mustard (Litwinienko \& Kasprzycka-Guttman, 1998), canola, corn and soy (Adhvaryu, Erhan, Liu, \& Perez, 2000), chia seeds and linseed (Grampone, Irigaray, Rodríguez, \& Sammán, 2013) and also blackberry and raspberry (Micić et al., 2015).

Integral isoconversional methods such as the classical method proposed by Ozawa, Flynn and Wall (OFW) (Ozawa, 1970), are able to provide the activation energy and pre exponential Arrhenius factor involved in lipid oxidation reaction. The oxidation temperature (T) is determined from the inflection point of the "heat flow versus temperature" curve obtained at a constant heating rate. The activation energy in initial instants of reaction is considered sufficient to allow the comparison between samples submitted to same experimental conditions (Litwinienko \& Kasprzycka-Guttman, 1998). Also, it is assumed that the oxidation reaction follows a pseudo first-order kinetics when oxygen in excess is used. A constant conversion is assumed for every onset oxidation temperature at different heating rates (OstrowskaLigeza et al., 2010).

Microencapsulation is defined as a process where a compound is surrounded by a wall material forming micrometric particles. This method has shown promising results in the encapsulation and protection of lipids, vitamins, peptides, fatty acids, antioxidants, minerals, and probiotics. It is efficient to prevent evaporation, chemical degradation, migration of substances to food, preservation and stabilization (Dordevic et al., 2015). Encapsulation is a viable approach to obtain oils in a powder form, facilitating manipulation and incorporation of oils in foodstuff. It may also protect lipids from atmospheric exposure, protecting them from oxidation and degradation and avoiding the formation of undesirable flavors and odors. In the case of mayonnaise, encapsulation could be a feasible way to prevent oil oxidation (Campo et al., 2017; Raudsepp, Brüggemann, Lenferink, Otto, \& Andersen, 2014).

To the best of our knowledge, no studies have been found in literature dealing with the incorporation of microencapsulated oils into mayonnaise. Microencapsulation may be an alternative to prevent the oil to be perceived sensorially and also to avoid oil oxidation which can impact negatively on physico-chemical properties, food processing and storage. Therefore, the aim of this work was to obtain mayonnaises containing microencapsulated chia seeds oil, baru oil and pumpkin seeds oil.

\section{Materials and methods}

\subsection{Materials}

Chia seeds, baru seeds and pumpkin seeds oils (Veris do Brasil Ltda) were stored at $-10{ }^{\circ} \mathrm{C}$ and protected from light until use (oils did not contain any kind of added antioxidants). Distilled water was used as the continuous phase to produce the microparticles. Stearic acid (SigmaAldrich, analytical grade) and sodium caseinate (Sigma-Aldrich, analytical grade) were used as wall material and stabilizer, respectively. Neutral ether-alcohol solution (2:1, v:v); phenolphthalein (Dinâmica, analytical grade) solution (1\%, w:v); sodium hydroxide (Dinâmica, analytical grade) solution 0.01 mol. $\mathrm{L}^{-1}$; methyl tricosanoate (23:0 Me, Sigma-Aldrich, chromatographic standard); isooctane (Dinâmica, chromatographic grade); esterifying reagent, methanolic sodium hydroxide solution 0.5 mol. $\mathrm{L}^{-1}$ and saturated sodium chlorate solution were used in the characterization analyzes. Fatty acids methyl esters (FAME) Mix C14-C24 (Sigma-Aldrich) was used as standards in gas chromatography. Synthetic air $\left(79 \% \mathrm{~N}_{2}, 21 \% \mathrm{O}_{2}\right)$ and nitrogen were used in the calorimetric experiments. $\mathrm{KBr}$ (Sigma-Aldrich, spectroscopic standard) was used in the FTIR analyses. Commercial mayonnaise was acquired from local market.

\subsection{Microparticles production}

Microparticles were obtained using the procedure described by Guimarães-Inácio et al. (2018). Briefly, the aqueous phase was prepared dissolving sodium caseinate $(0.275 \mathrm{~g})$ in distilled water $(250.0 \mathrm{~g})$ that was thereafter heated up to $75^{\circ} \mathrm{C}$ under gentle stirring ( 0.10 dispersed to continuous phase ratio, $10 \%$ solids content and $33 \%$ wt oil in the lipid phase). Separately, a jacketed borosilicate flask was connected to a thermostatic bath at $75^{\circ} \mathrm{C}$ and used to firstly melt stearic acid (16.75 g). Oils (chia seeds, pumpkin seeds or baru) $(8.25 \mathrm{~g}$ ) were then added to the flask under gentle stirring. After $1 \mathrm{~min}$, the aqueous phase was added to this mixture using a high efficiency disperser (Ultraturrax IKA, T25 equipped with a S25N10G probe) at $8600 \mathrm{rpm}$ during $5 \mathrm{~min}$. At the end of this step, the obtained dispersion was poured into an ice bath for quick quenching and solidification of the microparticles. Microparticles were freeze-dried (Liotop 101, $-50{ }^{\circ} \mathrm{C}$ and $100 \mu \mathrm{mHg}$ ) and stored at $-10{ }^{\circ} \mathrm{C}$ protected from light. The same procedure also was carried out to obtain microparticles without oil (blank microparticles) in order to evaluate the influence of oils on the particles properties.

\subsection{Oils and microparticles characterization}

Physico-chemical parameters (acidity and humidity index) of oils were determined in triplicate according to the methodologies described by the Adolfo Lutz Institute (2008). Fatty acids were determined and quantified by Gas Chromatography with Flame Ionization Detection (GC-FID, DANI model GC 1000, Milan, Italy), after trans-esterification procedure previously described (Barros et al., 2013), this procedure was performed in triplicate. Separation was performed in a Macherey-Nagel column (50\% cyanopropyl-methyl-50\% phenylmethylpolysiloxane, $30 \mathrm{~m} \times 0.32 \mathrm{~mm}$ i.d. $\times 0.25 \mu \mathrm{md}_{\mathrm{f}}$, Düren, Germany), with the following temperature ramp: initial temperature $50{ }^{\circ} \mathrm{C}$, held for $2 \mathrm{~min}$, $30^{\circ} \mathrm{C} \cdot \mathrm{min}^{-1} \mathrm{ramp}$ to $125^{\circ} \mathrm{C}, 5^{\circ} \mathrm{C} \cdot \mathrm{min}^{-1} \mathrm{ramp}$ to $160^{\circ} \mathrm{C}, 20^{\circ} \mathrm{C} \cdot \mathrm{min}^{-1}$ ramp to $180{ }^{\circ} \mathrm{C}, 3^{\circ} \mathrm{C} \cdot \mathrm{min}^{-1} \mathrm{ramp}$ to $200^{\circ} \mathrm{C}, 20^{\circ} \mathrm{C} \cdot \mathrm{min}^{-1} \mathrm{ramp}$ to $220^{\circ} \mathrm{C}$ and held for $15 \mathrm{~min}$. Hydrogen was used as the carrier gas, using a flow rate of $4.0 \mathrm{~mL} \cdot \mathrm{min}^{-1}$ ( $\left.0.61 \mathrm{bar}\right)$, measured at $50^{\circ} \mathrm{C}$. Split injection (1:40) was carried out at $250^{\circ} \mathrm{C}$. Fatty acid identification was performed by comparing the relative retention times of FAME standards (Supelco 37 Component FAME Mix, Sigma-Aldrich, St. Louis, MO, USA) with the samples. The results were expressed in relative percentage of each fatty acid.

Differential Scanning Calorimetry (DSC) was used to evaluate the thermal properties of the microparticles at a Perkin Elmer 4000 equipment at nitrogen flowrate of $50 \mathrm{~mL} \cdot \mathrm{min}^{-1}$ and $20{ }^{\circ} \mathrm{C} \cdot \mathrm{min}^{-1}$ from $0{ }^{\circ} \mathrm{C}$ to $440{ }^{\circ} \mathrm{C}$. Samples (approximately $10 \mathrm{mg}$ ) were put in closed aluminum sample holders. FTIR spectra were acquired using a Fourier Transform Infrared Spectroscopy (FTIR Shimadzu IR Affinity-1) working in transmittance mode at $2 \mathrm{~cm}^{-1}$ resolution from 4000 to 
$400 \mathrm{~cm}^{-1}$ by co-adding 32 scans. $\mathrm{KBr}$ pellets were prepared using a sample concentration of $1 \% \mathrm{wt}$ and spectra were normalized using the peak at $2918 \mathrm{~cm}^{-1}$ to allow comparison. Changes in lipid crystallinity were monitored by X-Ray diffraction analyses (XRD, Bruker D8 Advance) using Cu-Ka radiation at $40 \mathrm{KV}$ and $35 \mathrm{~mA}$ from $3^{\circ} 1060^{\circ}$ $(2 \theta)$ at $5.9^{\circ} \cdot \mathrm{min}^{-1}$. Morphology of the microparticles was evaluated by Scanning Electron Microscopy (SEM, Carl Zeiss - EVO MA 15) using backscattering detection. Samples were gold coated before analysis to avoid particles deterioration that may be caused by the electrons beam. Particles size distributions were determined by Laser Diffraction (Malvern Mastersizer 3000) using water (with 1\%wt Tween 80) as dispersant. Parameters $\mathrm{D}_{10}, \mathrm{D}_{50}$ and $\mathrm{D}_{90}$ were calculated from the cumulative size distributions at which the total volume includes $10 \%$, $50 \%$ and $90 \%$ of smaller microparticles, respectively.

Encapsulation efficiency was determined by Gas Chromatography. Oils or lyophilized microparticles $(20-30 \mathrm{mg}$ ) were transesterified (Barros et al., 2013) and the total amount of each fatty acid was determined by GC-FID ([FA $\left.]_{\text {total }}\right)$. Separately, free oil was removed from the particles surface by washing an aliquot of the microparticles $(1 \mathrm{~g})$ with $5 \mathrm{~mL}$ ethanol for $15 \mathrm{~s}$ (to avoid oil extraction) and filtered through a filter of $3 \mu \mathrm{m}$ porosity. Then, the washed microparticles were also esterified and analyzed by Gas Chromatography to determine the amount of fatty acid entrapped inside the microparticles ([FA $]_{\text {entrapped}}$ ). Encapsulation efficiency (EE) was calculated according to Eq. (1) and this procedure was carried out in duplicate.

$E E(\%)=\frac{[F A]_{\text {entrapped }}}{[F A]_{\text {total }}} \cdot 100$

Oxidative stability was determined by Differential Scanning Calorimetry (DSC, Perkin Elmer 4000). Oil or lyophilized microparticles (approximately $5 \mathrm{mg}$ ) were put in open aluminum holders under synthetic air flux $\left(79 \% \mathrm{~N}_{2}, 21 \% \mathrm{O}_{2}\right)$ at flow rate of $100 \mathrm{~mL} \cdot \mathrm{min}^{-1}$ from $0{ }^{\circ} \mathrm{C}$ to $440^{\circ} \mathrm{C}$. The evaluated heating rates were $1,5,10$ and $20^{\circ} \mathrm{C} \cdot \mathrm{min}^{-1}$ in duplicate. DSC calibration was performed for each analysis condition with zinc and indium standards $(429.75 \mathrm{~K}$ and $692.68 \mathrm{~K}$, respectively). The calculation of the activation energy (Ea in $\mathrm{kJ} . \mathrm{mol}^{-1}$ ) involved in the lipid oxidation reaction followed the method proposed by Ozawa, Flynn and Wall (OFW) (Ozawa, 1970) according to Eqs. (2) and (3), where $T$ is temperature (K), $R$ is universal gas constant $\left(8.3143 \mathrm{~J} \cdot \mathrm{mol}^{-1} \mathrm{~K}^{-1}\right), \beta$ is heating rate $\left(\mathrm{K} \cdot \mathrm{min}^{-1}\right)$ and $\mathrm{Ea}$ is activation energy ( $\mathrm{kJ} \cdot \mathrm{mol}^{-1}$ ) (Guimarães-Inácio et al., 2018; Litwinienko \& Kasprzycka-Guttman, 1998; Ostrowska-Ligeza et al., 2010).

$\log \beta=a T^{-1}+b$

$E a=-2,19 R \frac{d \log \beta}{d T^{-1}}$

The onset oxidation temperature ( $\mathrm{T}$ in $\mathrm{K}$ ) was found by extrapolating the baseline and the tangent line (leading edge) of each thermogram. $\beta$ is the heating rate (K.min $\left.{ }^{-1}\right)$, "a" and " $b$ " are the slope and intercept, respectively and $\mathrm{R}$ is the universal gas constant (8.3143 J.mol ${ }^{-1} \mathrm{~K}^{-1}$ ).

\subsection{Preparation and characterization of the mayonnaise containing the oil- loaded microparticles}

Oil-loaded and blank microparticles were added to commercial mayonnaise at a concentration of $2.5 \% \mathrm{wt}, 5.0 \% \mathrm{wt}$ and $7.5 \% \mathrm{wt}$. The lyophilized microparticles were manually mixed with the mayonnaise for 3 min (the same mixing behavior was carried out with the control sample (no addition of microparticles) to avoid the influence of sample manipulation on the rheological and texture analyses). Nutritional composition (protein, total lipids, ash and moisture) and energy content was determined according to the Instituto Adolfo Lutz (2008) methodologies in triplicate. Colorimetric analyses (Konica Minolta CR-400, D65 illuminant) were carried out to determine the parameters $L^{*}$ (luminosity), a* (from green to red) and $b^{*}$ (from blue to yellow). These parameters were used to calculate the tonality angle (Hue angle, $h^{\circ}$ ) and saturation (Chroma, $C^{*}$ ), according to Eqs. (4) and (5), respectively. This analysis was performed in duplicate with three measurements per each replica.

$h^{\circ}=\tan ^{-1}\left(\frac{b^{*}}{a^{*}}\right)$

$C^{*}=\sqrt{a^{*^{2}}+b^{*^{2}}}$

Evaluation of the rheological behavior was performed at 25 and $37^{\circ} \mathrm{C}$ (representing room temperature and the average human body temperature, respectively). A rheometer (Brookfield DV-III Ultra) with spindle speed from zero to $100 \mathrm{rpm}$ was used with measurements made in duplicate using a new sample to avoid interferences due to the shear history on the sample. The parameters of the Bingham, Casson and Herschel-Bulkley models (Eqs. (6)-(8), respectively) were calculated to determine the flow type, thixotropy and the presence of hysteresis using the graphical representations. In these equations $\sigma$ is the shear stress (Pa), $\sigma_{0}$ is yield stress (Pa), $\eta_{a}$ is limiting viscosity (Pa.s), $\dot{\gamma}$ is shear rate $\left(\mathrm{s}^{-1}\right), k_{c}$ is viscosity at infinite shear rate (Pa.s), $k$ is consistency index $\left(\mathrm{Pa} . \mathrm{s}^{n}\right.$ ) and $n$ is the flow behavior index (dimensionless) (Chivero et al., 2016).

$\sigma=\sigma_{0}+\eta_{a} \cdot \dot{\gamma}$

$\sigma^{0,5}=\sigma_{0}^{0,5}+k_{c} \cdot \dot{\gamma}^{0,5}$

$\sigma=\sigma_{0}+k \cdot \dot{\gamma}^{n}$

Texture parameters were determined in triplicate using a TA.XT Express Stable Micro Systems texturometer equipped with a compression probe ( $35 \mathrm{~mm}$ diameter) and a $10 \mathrm{~kg}$ cell. Samples were placed into cylindrical containers with $50 \mathrm{~mm}$ diameter and $75 \mathrm{~mm}$ height, inserted up to $40 \mathrm{~mm}$ and submitted to compression of $50 \%$ of depth at a speed of $1 \mathrm{~mm} . \mathrm{s}^{-1}$ (Di Mattia et al., 2015). Firmness property was calculated from the maximum force recorded; area under the curve up to the maximum peak was used to calculate the consistency; cohesiveness and work of adhesion were measured by the maximum negative force and the area of the negative region of the curve, respectively (Liu, Xu, \& Guo, 2007).

Sensory evaluation was carried out using the ranking preference test with 60 untrained panelists. The project was approved by the Ethics Committee in Research of Federal University of Technology - Paraná UTFPR under the protocol number 2.341.697 on October 10, 2017, as being in accordance with Brazilian regulations. Control sample (without microparticles) and samples with 2.5\%wt and 5.0\%wt particles concentration were evaluated and, for each sample, approximately $0.7 \mathrm{~g}$ of mayonnaise were placed on a toast. Panelist received, simultaneously, three coded samples at a random order, a glass of mineral water and an evaluation form. The panelist was asked to drink the water, taste the samples from left to right and order them according to their preference (ISO 8587, 2006). Results were statistically analyzed by the Friedman test at 5\% significance level (Fuchs et al., 2013).

\section{Results and discussion}

\subsection{Oils characterization}

Gas Chromatography results for fatty acids composition present in the chia seeds oil, pumpkin seeds oil and baru oils are presented in Table 1 (expressed as fatty acid relative percentage). Retention times and identification are shown in Fig. S1 (Supplementary Material). Acidity index and humidity content of the oils, are also presented in Table 1.

Acidity index is an indicative of the oil preservation. Rancidity is accompanied by the formation of free fatty acids, with a maximum 
Table 1

Percentage composition of the fatty acids present in oils and physico-chemical characteristics.

\begin{tabular}{llll}
\hline Fatty acids & Chia & Pumpkin seed & Baru \\
\cline { 2 - 4 } & \multicolumn{2}{l}{$\%$ fatty acid for each oil } \\
\hline C16:0 & $4.46 \pm 0.02$ & $10.74 \pm 0.01$ & $6.27 \pm 0.10$ \\
C18:0 & $2.38 \pm 0.01$ & $5.12 \pm 0.04$ & $3.72 \pm 0.09$ \\
C18:1n-9 & $4.02 \pm 0.01$ & $19.72 \pm 0.01$ & $42.42 \pm 0.53$ \\
C18:2n-6 & $14.74 \pm 0.01$ & $56.21 \pm 0.02$ & $36.17 \pm 0.20$ \\
C18:3n-3 & $73.63 \pm 0.02$ & $6.97 \pm 0.03$ & $0.30 \pm 0.02$ \\
C20:0 & $0.17 \pm 0.01$ & $0.37 \pm 0.01$ & $1.04 \pm 0.03$ \\
C20:1 & $0.10 \pm 0.01$ & $0.10 \pm 0.01$ & $2.39 \pm 0.04$ \\
SFA (\%) & $7.20 \pm 0.03$ & $16.77 \pm 0.03$ & $18.32 \pm 0.26$ \\
MUFA (\%) & $4.17 \pm 0.01$ & $19.96 \pm 0.01$ & $45.10 \pm 0.48$ \\
PUFA (\%) & $88.64 \pm 0.02$ & $63.27 \pm 0.04$ & $36.58 \pm 0.23$ \\
PUFA:SFA & $12.31 \pm 0.05$ & $3.77 \pm 0.01$ & $1.99 \pm 0.03$ \\
n-6:n-3 & $0.20 \pm 0.01$ & $8.06 \pm 0.03$ & $120.57 \pm 8.07$ \\
Acidity index & $0.04 \pm 0.01$ & $0.07 \pm 0.02$ & $0.02 \pm 0.01$ \\
$\quad\left(g_{\text {oleic acid. } 100 \mathrm{~g}_{\text {oil }}{ }^{-1} \text { ) }}\right.$ & & & \\
Humidity (\%) & $0.96 \pm 0.45$ & $0.44 \pm 0.08$ & $0.33 \pm 0.10$ \\
\hline
\end{tabular}

SFA: Saturated Fatty Acids; MUFA: Monounsaturated Fatty Acids; PUFA: Polyunsaturated Fatty Acids. Palmitic acid (C16:0); Stearic acid (C18:0); Oleic acid (C18:1n9c); Linoleic acid (C18:2n6c); $\alpha$-Linolenic acid (C18:3n3c); Arachidic acid (C20:0); Eicosenoic acid (C20:1c). Less abundant fatty acids present: Myristic acid (C14:0); Pentadecanoic acid (C15:0); Palmitoleic acid (C16:1); Heptadecanoic acid (C17:0); cis-11,14-Eicosadienoic acid (C20:2c); Arachidonic acid (C20:4n6); cis-11, 14, 17-Eicosatrienoic acid (C20:3n3), Heneicosanoic acid (C21:0); cis-5,8,11,14,17-Eicosapentaenoic acid (C20:5n3); Behenic acid (C22:0); Erucic acid (C22:1n9) Tricosanoic acid (C23:0); Lignoceric acid (C24:0).

acidity permitted in oils of $0.4 \mathrm{~g}$ oleic acid. $100 \mathrm{~g}_{\text {oil }}{ }^{-1}$ (Codex Alimentarius Commission, 1999). Variations among available literature data may be explained by the quality of the raw material, degree of purity, and processing and preservation conditions. Values on Table 1 are in accordance with values reported in some works. Moisture content represents an important control parameter for oils, fats and oily seeds because stability decreases with increasing moisture content (Kaijser, Dutta, \& Savage, 2000). From the obtained results, it can be concluded that the studied oils were preserved and presented low level of rancidity.

Up to twenty fatty acids methyl ester were identified (data not shown) and Table 1 presents only the main FAME present in the samples. The most abundant fatty acids in chia seeds oil were $\alpha$-linolenic and linoleic acid, whereas for pumpkin seeds and baru the major acids were linoleic and oleic acids, respectively. Among the saturated fatty acids, the highest concentration was palmitic acid in pumpkin seeds oil and the highest total saturated fatty acid values were found in baru and pumpkin. Values for chia seeds oil and baru oil are in accordance with literature data (Silva et al., 2015; Ullah, Nadeem, Ayaz, Imran, \& Tayyab, 2016). Procida, Stancher, Cateni, and Zacchigna (2013) found values around $0.29 \% \alpha$-linolenic acid, 48.29\% linoleic acid and 38.33\% oleic acid when carrying out similar studies to identify fatty acids in commercial pumpkin seed oils for diet and therapeutic purposes.

\subsection{Microparticles characterization}

Encapsulation efficiency (\%) for omega-3 and omega-6, PUFAS and MUFAs concentration, particle sizes $\left(\mathrm{D}_{10}, \mathrm{D}_{50}\right.$ and $\left.\mathrm{D}_{90}\right)$ and melting temperatures and fusion enthalpies are presented in Table 2 (DSC thermograms for the oil-loaded microparticles, together with the blank microparticles are showed in Fig. S2, Supplementary Material). Fig. 1 presents the images obtained by Scanning Electron Microscopy of the oil-loaded microparticles and blank microparticles (no oil added).

Agglomerated, irregular particles were formed and no remarkable differences could be visually found in all cases. Micrometric particles
Table 2

Encapsulation efficiency, PUFAS and MUFAs concentration, particle sizes $\left(\mathrm{D}_{10}\right.$, $\mathrm{D}_{50}$ and $\left.\mathrm{D}_{90}\right)$ and enthalpy $\left(\Delta \mathrm{H}_{\mathrm{m}}\right)$ and melting temperatures $\left(\mathrm{T}_{\mathrm{m}}\right)$ for the produced microparticles.

\begin{tabular}{|c|c|c|c|c|c|}
\hline & & Chia seeds & Pumpkin seeds & Baru & Blank \\
\hline \multirow[t]{2}{*}{$\begin{array}{l}\text { Encapsulation } \\
\text { efficiency } \\
(\%)\end{array}$} & $\begin{array}{l}\text { 18:2n6 } \\
\text { (omega- } \\
6 \text { ) }\end{array}$ & $99.0 \pm 1.4$ & $88.2 \pm 4.3$ & $98.9 \pm 6.9$ & - \\
\hline & $\begin{array}{l}18: 3 n 3 \\
\text { (omega- } \\
3 \text { ) }\end{array}$ & $100.5 \pm 1.4$ & $88.8 \pm 6.1$ & $105.7 \pm 4.0$ & - \\
\hline \multicolumn{2}{|c|}{ PUFA concentration } & 0.29 & 0.18 & 0.12 & - \\
\hline \multicolumn{2}{|c|}{$\begin{array}{r}\text { MUFA concentration } \\
\quad\left(g_{\text {MUFA }} / g_{\text {particles }}\right)\end{array}$} & 0.04 & 0.06 & 0.15 & - \\
\hline \multicolumn{2}{|l|}{$\mathrm{D}_{10}(\mu \mathrm{m})$} & 3.6 & 4.6 & 4.5 & 3.1 \\
\hline \multicolumn{2}{|l|}{$\mathrm{D}_{50}(\mu \mathrm{m})$} & 24.1 & 27.4 & 31.1 & 31.1 \\
\hline \multicolumn{2}{|l|}{$\mathrm{D}_{90}(\mu \mathrm{m})$} & 58.6 & 66.9 & 98.1 & 86.4 \\
\hline \multirow{2}{*}{\multicolumn{2}{|c|}{$\begin{array}{l}\Delta \mathrm{H}_{\mathrm{m}}\left(\mathrm{J} \cdot \mathrm{g}^{-1}\right) \\
\mathrm{T}_{\mathrm{m}}\left({ }^{\circ} \mathrm{C}\right)\end{array}$}} & 185.0 & 179.9 & 179.8 & 248.9 \\
\hline & & 72.9 & 72.0 & 72.0 & 76.4 \\
\hline
\end{tabular}

were produced with $90 \%$ of the particles presenting diameters roughly inferior to $100 \mu \mathrm{m}$. This is an interesting feature because small particles usually present lower sensory perception when added to foodstuff. Quite high values for the encapsulation efficiency were found, which might be justified by to the affinity between the stearic acid and the fatty acids due to their hydrophobic nature. Oil encapsulation is also favored by low oil to encapsulant ratio because oil migration to the particles surface is minimized in such condition. High encapsulation efficiency is desired because it means that most of the oil is inside the solid lipid matrix and thus not in direct contact with atmospheric air.

It is worth mentioning that, under gaseous nitrogen atmosphere, DSC allows monitoring the material physical state because the melting temperature and the energy involved in the process provides information about physical properties of compounds. Melting temperature and enthalpy of the oil-loaded particles were smaller than the blank microparticles evidencing the efficient oil encapsulation (Fig. S2). This is supported by the fact that the decrease in enthalpy values was not linear with the decrease in stearic acid concentration in the particles. Enthalpy decrease is also associated with a disorder crystalline structure caused by the presence of the oil (Souza et al., 2015). Similar behavior was also verified by Guimarães-Inácio et al. (2018) with carnauba wax microparticles containing chia oil.

Microparticles were characterized by Fourier Transform Infrared and X-Ray Diffraction in order to confirm if oils were entrapped in the stearic acid matrix (Figs. S3 and S4Supplementary Material). Infrared spectra of oils before encapsulation and oil-loaded microparticles showed absorption bands at $3010 \mathrm{~cm}^{-1}$ and $1740 \mathrm{~cm}^{-1}$, assigned to $\mathrm{C}=\mathrm{C}-\mathrm{H}$ and $\mathrm{C}=\mathrm{O}$ bonds, respectively (Freiberger et al., 2015). Blank microparticles did not present the band at $3010 \mathrm{~cm}^{-1}$ since there is no unsaturation in the carbon chain of stearic acid. Carbonyl absorption is attributed to ester groups present in triacylglycerols. Characteristic bands of oils were attenuated in the microparticles sample suggesting that oils are located inside the particles, thus indicating their efficient encapsulation (Freiberger et al., 2015; Guimarães-Inácio et al., 2018).

X-ray diffractograms showed an intense peak at $21.5^{\circ}$ and a less intense one at $24^{\circ}$ characteristic of stearic acid, indicating the crystalline nature of this compound (Wong, Heng, \& Chan, 2015). In fact, lipids can be found in three polymorphic forms, namely $\alpha$ (unstable form), $\beta$ (most stable form with an intermediate packed density) and $\beta^{\prime}$ (metastable form with a denser packing) (Ciftci \& Temelli, 2016). Although no appreciable difference between blank and oil-loaded microparticles was detected, there was a decrease in the intensity of the crystalline peaks suggesting that crystallinity degree decreased due to the presence of oils. It is also possible to observe the appearance of an amorphous peak around $19^{\circ}$ in the oil-loaded samples, also indicating a 
(a)

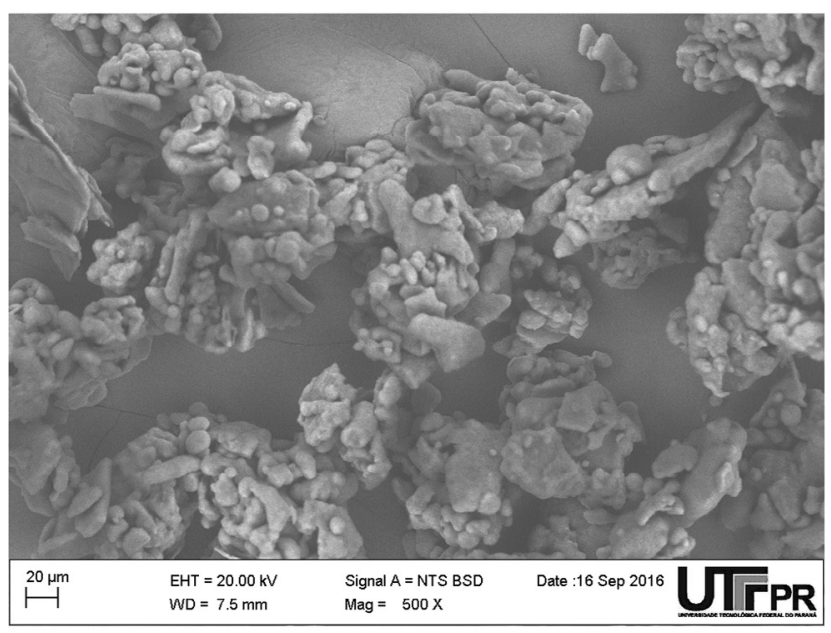

(b)

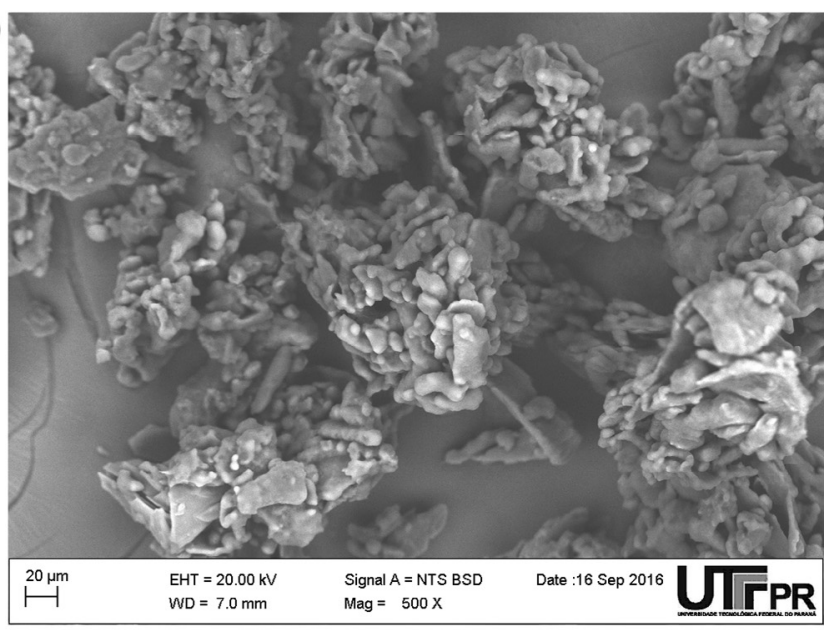

(c)

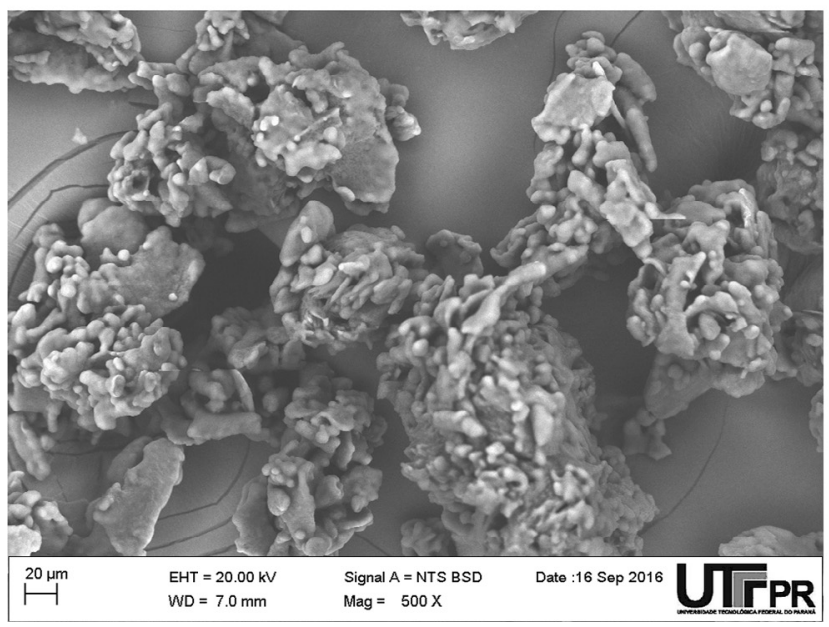

(d)

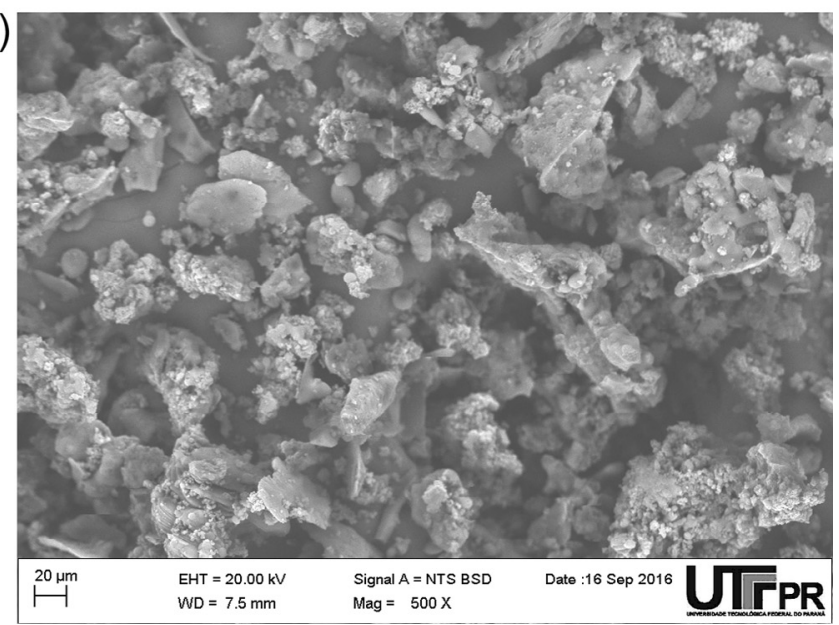

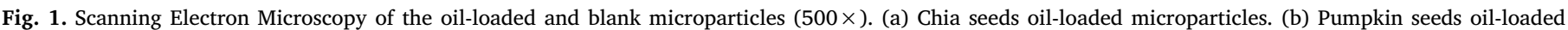
microparticles. (c) baru oil-loaded microparticles. (d) Blank microparticles (no added oil).

decrease in crystallinity (Sagiri, Singh, Pal, Banerjee, \& Basak, 2015).

The physico chemical characterization of the oil-loaded microparticles strongly indicated that, in all cases, oil was efficiently encapsulated in the stearic acid matrix, decreasing their crystallinity and melting temperature.

\subsection{Thermal stability}

Table 3 shows the respective Activation Energy (Ea) and representative values of correlation coefficient (R2) for oils and oil-loaded microparticles. They were calculated using data in Table S1 and the DSC curves at different heating rates $(\beta)$ presented in Fig. S5, Supplementary Material.

Good fittings were found for all cases, with linear models statistically significant $(\mathrm{p}<0.05)$, indicating that they describe adequately the experimental data. An increase in the activation energy was observed after encapsulation (50\%, 15\% and 33\%, respectively for chia seeds, pumpkin seeds and baru oils), indicating higher stability and effective protection against oxidation. Oils in the microparticles were less prone to react with atmospheric oxygen due to the solid encapsulant matrix. This means that the solid barrier could reduce heat and oxygen flow to the oil preventing the formation of hydroperoxides and other degradation products (González, Martínez, Paredes, León, \& Ribotta, 2016). The lower increase in stability observed with pumpkin oil could related with the lower encapsulation efficiency (Table 2) when compared to other oils. It is worth noting that the onset oxidation
Table 3

Activation energy and correlation coefficient for in natura oils and oil-loaded microparticles.

\begin{tabular}{llll}
\hline Oil & & Activation Energy(Ea, kJ.mol $\left.{ }^{-1}\right)$ & $\mathrm{R}^{2}(-)$ \\
\hline Chia seeds & oil & $76.4 \pm 9.1$ & 0.999 \\
& microcapsules & $114.5 \pm 5.2$ & 0.993 \\
Pumpkin seeds & oil & $96.7 \pm 0.7$ & 0.989 \\
& microcapsules & $111.6 \pm 4.5$ & 0.990 \\
Baru & oil & $74.2 \pm 4.0$ & 0.965 \\
& microcapsules & $98.6 \pm 11.5$ & 0.951 \\
\hline
\end{tabular}

temperature is often used to compare the stability of edible oils (Micić et al., 2015). Lipid oxidation is a reaction initiated by the formation of free radicals and, in the case of edible oils, the decomposition of unsaturated fatty acid occurs at the beginning of the process.

From the above results of oil composition, particles characterization and oxidative stability study it is possible to conclude that the micrometric microparticles were able to protect, against degradation, the oil entrapped inside the solid lipid matrix. This indicates that such results may be used to formulated PUFAs-rich foodstuff.

\subsection{Mayonnaise characterization}

Nutritional composition of the mayonnaise (without microparticles), 
Table 4

Properties of the mayonnaises containing oil-loaded microparticles or respective oils.

\begin{tabular}{|c|c|c|c|c|c|c|c|c|c|}
\hline \multirow[t]{2}{*}{ Sample } & \multirow{2}{*}{$\begin{array}{l}\text { Microparticles } \\
\text { added (\%) }\end{array}$} & \multirow{2}{*}{$\begin{array}{l}\text { PUFAs concentration } \\
\left(\mathrm{g}_{\text {PUFA }} / 100 g_{\text {mayonnaise }}\right)\end{array}$} & \multicolumn{3}{|c|}{ Color parameters } & \multicolumn{4}{|c|}{ Texture parameters } \\
\hline & & & $\mathrm{L}^{*}$ & $C^{*}$ & $\mathrm{~h}^{\circ}$ & $\begin{array}{l}\text { Firmness } \\
(\mathrm{N})\end{array}$ & $\begin{array}{l}\text { Cohesiveness } \\
(\mathrm{N})\end{array}$ & $\begin{array}{l}\text { adhesion work } \\
\text { (N.s) }\end{array}$ & $\begin{array}{l}\text { Consistency } \\
\text { (N.s) }\end{array}$ \\
\hline $\begin{array}{c}\text { Control sample (mayonnaise } \\
\text { without microparticles) }\end{array}$ & 0 & - & $89.1 \pm 0.3$ & $23.7 \pm 0.2$ & $80.3 \pm 0.7$ & $1.3 \pm 0.1$ & $-1.0 \pm 0.1$ & $-16.1 \pm 1.4$ & $19.8 \pm 3.3$ \\
\hline \multirow[t]{3}{*}{ Chia oil } & 2.5 & 0.73 & $88.7 \pm 0.5$ & $23.3 \pm 0.3$ & $79.4 \pm 0.7$ & $1.5 \pm 0.1$ & $-1.1 \pm 0.1$ & $-18.0 \pm 1.5$ & $23.8 \pm 2.0$ \\
\hline & 5.0 & 1.45 & $88.5 \pm 0.2$ & $23.4 \pm 0.3$ & $79.6 \pm 0.4$ & $1.4 \pm 0.1$ & $-1.1 \pm 0.0$ & $-17.3 \pm 0.2$ & $21.1 \pm 0.4$ \\
\hline & 7.5 & 2.18 & $88.7 \pm 0.4$ & $23.7 \pm 0.1$ & $80.1 \pm 0.2$ & $1.5 \pm 0.0$ & $-1.1 \pm 0.0$ & $-17.3 \pm 0.1$ & $22.1 \pm 1.0$ \\
\hline \multirow[t]{3}{*}{ Pumpkin seeds oil } & 2.5 & 0.45 & $88.4 \pm 0.4$ & $23.9 \pm 0.2$ & $80.8 \pm 0.6$ & $1.4 \pm 0.0$ & $-1.1 \pm 0.0$ & $-16.6 \pm 0.0$ & $21.8 \pm 1.3$ \\
\hline & 5.0 & 0.90 & $88.2 \pm 0.3$ & $23.5 \pm 0.3$ & $79.8 \pm 0.5$ & $1.3 \pm 0.1$ & $-0.9 \pm 0.1$ & $-14.7 \pm 0.8$ & $18.3 \pm 2.8$ \\
\hline & 7.5 & 1.35 & $87.9 \pm 0.3$ & $23.6 \pm 0.1$ & $79.8 \pm 0.4$ & $1.4 \pm 0.1$ & $-1.1 \pm 0.1$ & $-18.1 \pm 1.6$ & $23.9 \pm 1.1$ \\
\hline \multirow[t]{3}{*}{ Baru oil } & 2.5 & 0.30 & $88.4 \pm 0.8$ & $23.9 \pm 0.3$ & $80.3 \pm 0.7$ & $1.3 \pm 0.1$ & $-0.9 \pm 0.1$ & $-15.3 \pm 0.3$ & $19.4 \pm 1.6$ \\
\hline & 5.0 & 0.60 & $88.3 \pm 0.7$ & $23.6 \pm 0.3$ & $79.9 \pm 0.7$ & $1.4 \pm 0.0$ & $-1.1 \pm 0.0$ & $-17.3 \pm 0.2$ & $20.8 \pm 1.0$ \\
\hline & 7.5 & 0.90 & $88.5 \pm 0.3$ & $23.8 \pm 0.2$ & $80.3 \pm 0.5$ & $1.4 \pm 0.2$ & $-1.0 \pm 0.2$ & $-16.4 \pm 1.7$ & $20.2 \pm 3.1$ \\
\hline
\end{tabular}

was $22.98 \pm 0.44 \mathrm{~g} .100 \mathrm{~g}^{-1}$ for humidity, $1.49 \pm 0.03 \mathrm{~g} .100 \mathrm{~g}^{-1}$ for ash, $70.00 \pm 0.53 \mathrm{~g} .100 \mathrm{~g}^{-1}$ for lipids, $5.56 \pm 0.03 \mathrm{~g} .100 \mathrm{~g}^{-1}$ for carbohydrates and $652.24 \pm 0.05 \mathrm{kcal} .100 \mathrm{~g}^{-1}$ for energy content, which are in agreement with those reported in the product label (no protein amount was detected). Liu et al. (2007) reported similar values when evaluated centesimal composition of mayonnaise based on soybean oil, where small discrepancies may be related to different proportions of ingredients used in the formulation.

Color parameters $\left(\mathrm{L}^{*}, \mathrm{C}^{*}\right.$ and $\mathrm{h}^{\circ}$ ) and texture parameters (Firmness, cohesiveness, adhesion work and consistency) are presented in Table 4. Images of the formulated mayonnaise containing $7.5 \% \mathrm{wt}$ microparticles are presented in Fig. 2.

All samples presented high luminosity, tendency to green $\left(-\mathrm{a}^{*}\right)$ and yellow $\left(+b^{*}\right)$ and relatively low color intensity $\left(C^{*}\right)$ and a hue angle $\left(h^{\circ}\right)$ of approximately $80^{\circ}$, which means that all formulated mayonnaise samples presented an opaque yellowish color. When compared to control sample (mayonnaise without microparticles) the addition of chia oil-loaded and baru oil-loaded microparticles did not change the mayonnaise color significantly ( $\mathrm{p}>0.05$ ). For the pumpkin seeds oil, luminosity $\left(\mathrm{L}^{*}\right)$ of the samples with $5.0 \% \mathrm{wt}$ and $7.5 \% \mathrm{wt}$ microparticles differed significantly if compared to the control sample $(p<0.05)$. This was probably due to the fact that pumpkin seeds oil itself is darker than the other oils leading to darker particles as well. However, as observed in Fig. 2, all formulated mayonnaises are visually similar. Other authors have reported minor color variations caused by the addition of plant extracts (Altunkaya et al., 2013), and also variations in the mayonnaise formulation (Rahmati et al., 2014).

Firmness represents the maximum force measured by the equipment, indicating how firm is the sample and the recorded peak force area indicates sample consistency (Liu et al., 2007). Cohesiveness is a direct function of the work needed to overcome the internal bonds of material, hence it indicates how much the structure deforms before breaking when extended. Adhesion work is a representation of cohesiveness, consistency and viscosity of the sample, which indicates how much the sample adhered and resist in return of equipment probe to its initial state. As the value increases, higher the probe resistance (Liu et al., 2007). Samples presented low firmness and cohesiveness, but considerable consistency and adhesion work values, similarly to those found in the literature (Di Mattia et al., 2015). Texture parameters were statistically equal for all evaluated samples, indicating that the microparticles did not interfere in the mechanical texture when added up to $7.5 \%$ wt.

Flow and viscosity curves for the control and mayonnaise containing the oil-loaded microparticles were obtained at 25 and $37{ }^{\circ} \mathrm{C}$ (Figs. S6-S8, Supplementary Material). Rheological behavior was mathematically modeled using Casson, Binghan and Hurschel-Bulkley equations, and the parameters found are presented in Tables S2 and S3 (Supplementary Material).
Control mayonnaise and the mayonnaise containing microparticles presented non-Newtonian (pseudoplastic) flow evidenced by the apparent viscosity for increasing shear rates. Thixotropic behavior and the presence of hysteresis were found for both tested temperatures. However, hysteresis was slightly reduced due the addition of the microparticles when compared to the control sample, indicating a reduction in thixotropy. Also, a viscosity increase was detected in the case of chia seeds and pumpkin seeds oil-loaded microparticles, but not with the baru oil. Changes in viscosity due to the addition of protein microparticles and pectin in mayonnaise are reported in the literature (Chang et al., 2017).

Reduction in shear rate was observed at $25^{\circ} \mathrm{C}$ caused by the increase in particles concentration. At this temperature, the system presented higher viscosity when compared with $37^{\circ} \mathrm{C}$, which limited the measurements at higher rates. The exception occurred only in the sample containing 7.5\%wt baru oil, due to its lower viscosity. The effect of temperature can be seen in the tests performed at $37^{\circ} \mathrm{C}$ where the reduction in shear rate did not occur due to its lower viscosity.

The second part of each curve (decreasing shear rates) was used to obtain the mathematical models (Tables S2 and S3). Hurschel-Bulkley (HB) model was the most reliable as observed by the lower errors and better correlation coefficients obtained. For this model, an increase in consistency index $(\mathrm{K})$ was observed in the microparticles-loaded samples when compared to control mayonnaise. Consistency indexes (K) were smaller at $37^{\circ} \mathrm{C}$ than at $25^{\circ} \mathrm{C}$ confirming the decrease in viscosity due to the increase in temperature. Consistency index also increased as the microparticles concentration increased. However, for baru oil microparticles this behavior occurred until 5.0\%wt addition and then a decrease in shear stress was observed for both studied temperatures. This phenomenon may be related to the disruption of the three-dimensional network of mayonnaise microstructure, causing a decrease in tension (Liu et al., 2007).

\subsection{Sensory analysis}

The ranking preference test was applied to panelists in order to determine if consumers would be able to differentiate between the mayonnaise containing microparticles $(2.5 \%$ and $5.0 \%$ added $)$ and the control sample (mayonnaise with no added microparticles). Friedman test at 5\% significance level showed that mayonnaise samples did not differ from control. This is an important finding because it indicates that PUFAs-rich mayonnaises could be available to consumers without outperforming conventional mayonnaise or affecting its sensorial perception. This also corroborates the texture and color analyses in which no, or minor, differences were detected among samples. The addition of oils in mayonnaise was investigated by Di Mattia et al. (2015) and panelists were able to find sensory differences depending on the used oil. 
(a)

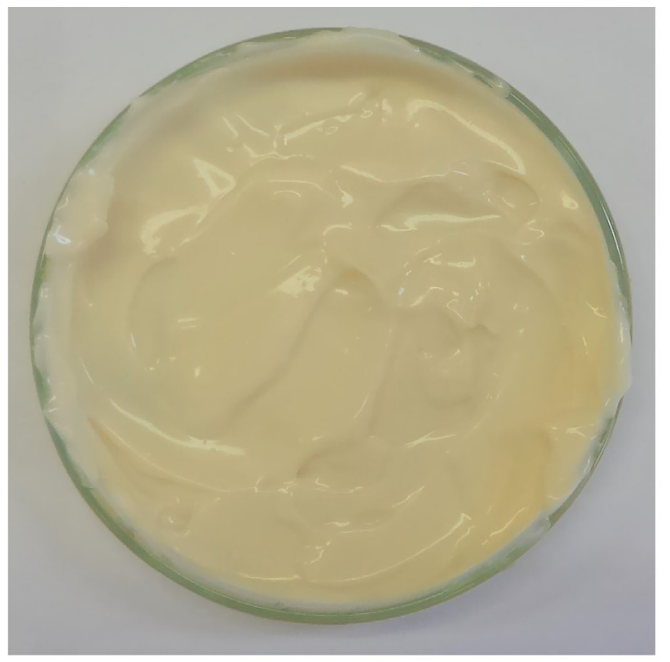

(c)

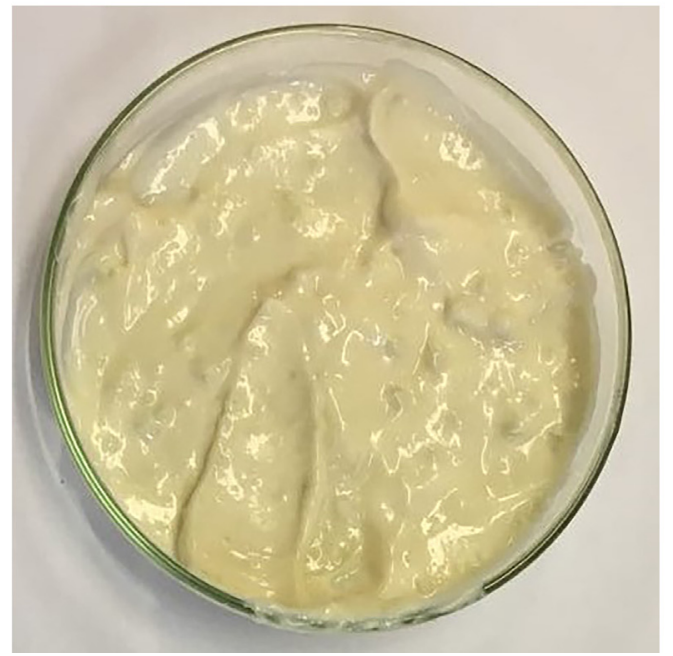

(b)

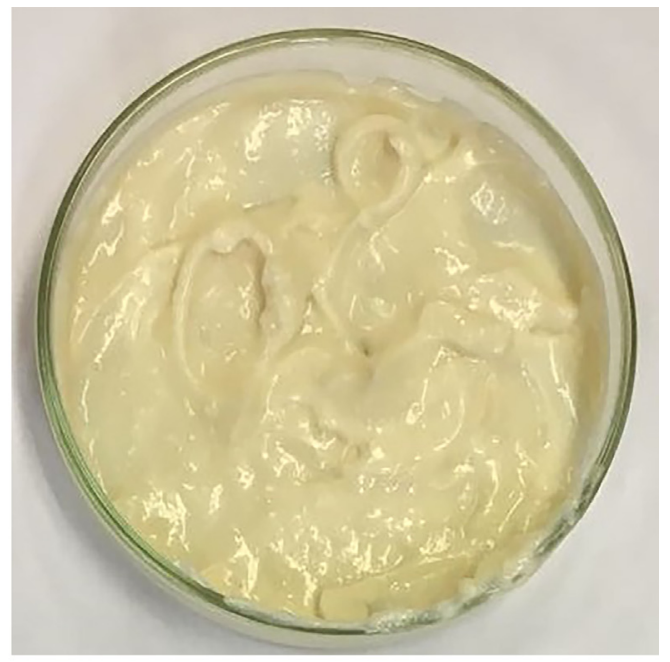

(d)

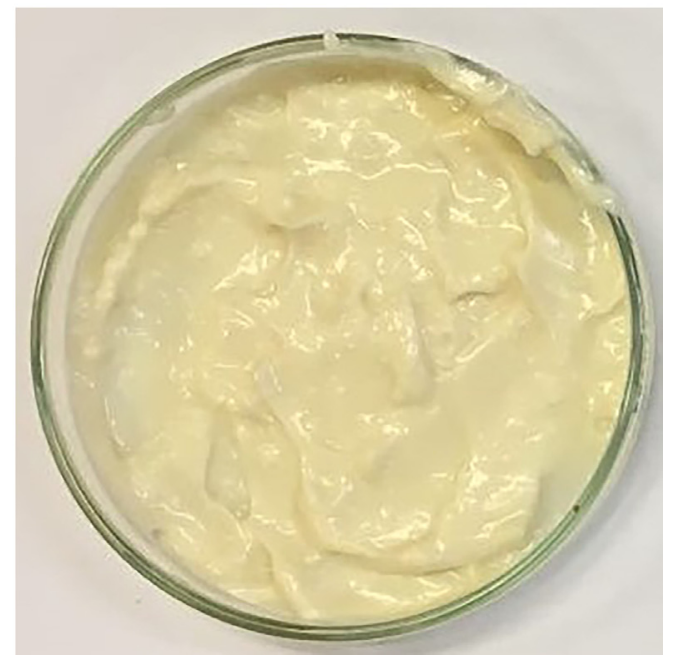

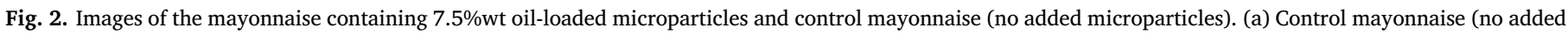
microparticles). (b) chia oil-loaded microparticles. (c) pumpkin seeds oil-loaded microparticles. (d) baru oil-loaded microparticles.

\section{Conclusions}

Mayonnaise containing microencapsulated oils (chia seeds, pumpkin seeds and baru) were obtained as a source of poly-unsaturated fatty acids (PUFAs). High values of encapsulation efficiency for omega 3 and omega 6 were achieved mainly due to the affinity between the oils and stearic acid (encapsulant). Oxidative stability of the oils was improved by encapsulation as demonstrated by the non-isothermal Differential Scanning Calorimetry analysis coupled with the OFW method.

Microparticles were added to mayonnaise at $2.5 \% \mathrm{wt}$ and $5.0 \% \mathrm{wt}$. Viscosity increased due to the presence of the microparticles but rheological behavior and mechanical texture were not affected. Color was only affected in the case of pumpkin seeds oil-loaded microparticles. Sensory tests performed with mayonnaise added with $2.5 \% \mathrm{wt}$ and $5.0 \%$ wt microparticles demonstrated that consumers were not able to differentiate the samples from the control sample (mayonnaise with no added microparticles) for all tested oils. Gathered results showed that encapsulation effectively protected the oils against oxidative degradation and that enriched mayonnaise can be obtained with encapsulated edible oils with high nutritional value.

\section{Acknowledgements}

Authors thank CAPES, CNPq and Fundação Araucária for the support. The authors are grateful to the Foundation for Science and Technology (FCT, Portugal) and FEDER under Programme PT2020 for financial support to CIMO (UID/AGR/00690/2013) and L. Barros contract.

\section{Conflicts of interest}

None.

\section{Appendix A. Supplementary data}

Supplementary data associated with this article can be found, in the online version, at https://doi.org/10.1016/j.foodchem.2018.09.015.

\section{References}

Adhvaryu, A., Erhan, S. Z., Liu, Z. S., \& Perez, J. M. (2000). Oxidation kinetic studies of oils derived from unmodified and genetically modified vegetables using pressurized differential scanning calorimetry and nuclear magnetic resonance spectroscopy. Thermochimica Acta, 364(1-2), 87-97. https://doi.org/10.1016/S0040-6031(00) 00626-2.

ALIMENTARIUS, C. (1999). Codex Standard for Edible Fats and Oils Not Covered By Individual Standards., Roma: FAO: https://doi.org/10.1017/CBO9781107 415324. 004.

Altunkaya, A., Hedegaard, R. V., Harholt, J., Brimer, L., Gökmen, V., \& Skibsted, L. H. (2013). Oxidative stability and chemical safety of mayonnaise enriched with grape seed extract. Food \& Function, 4(11), 1647-1653. https://doi.org/10.1039/ c3fo60204d. 
Alvarez-Sabatel, S., Martínez de Marañón, I., \& Arboleya, J. C. (2018). Impact of oil and inulin content on the stability and rheological properties of mayonnaise-like emulsions processed by rotor-stator homogenisation or high pressure homogenisation (HPH). Innovative Food Science and Emerging Technologies, 48, 195-203. https://doi. org/10.1016/j.ifset.2018.06.014.

Barros, L., Pereira, E., Calhelha, R. C., Dueñas, M., Carvalho, A. M., Santos-Buelga, C., \& Ferreira, I. C. F. R. (2013). Bioactivity and chemical characterization in hydrophilic and lipophilic compounds of Chenopodium ambrosioides L. Journal of Functional Foods, 5(4), 1732-1740. https://doi.org/10.1016/j.jff.2013.07.019.

Chang, C., Li, J., Li, X., Wang, C., Zhou, B., Su, Y., \& Yang, Y. (2017). Effect of protein microparticle and pectin on properties of light mayonnaise. LWT - Food Science and Technology, 82, 8-14. https://doi.org/10.1016/j.lwt.2017.04.013.

Chivero, P., Gohtani, S., Yoshii, H., \& Nakamura, A. (2016). Assessment of soy soluble polysaccharide, gum arabic and OSA-Starch as emulsifiers for mayonnaise-like emulsions. LWT - Food Science and Technology, 69, 59-66. https://doi.org/10.1016/j. lwt.2015.12.064.

Ciftci, O. N., \& Temelli, F. (2016). Formation of solid lipid microparticles from fully hydrogenated canola oil using supercritical carbon dioxide. Journal of Food Engineering, 178, 137-144. https://doi.org/10.1016/j.jfoodeng.2016.01.014.

De Campo, C., dos Santos, P. P., Costa, T. M. H., Paese, K., Guterres, S. S., de Rios, A. O., \& Flôres, S. H. (2017). Nanoencapsulation of chia seed oil with chia mucilage (Salvia hispanica L.) as wall material: Characterization and stability evaluation. Food Chemistry, 234, 1-9. https://doi.org/10.1016/j.foodchem.2017.04.153.

Di Mattia, C., Balestra, F., Sacchetti, G., Neri, L., Mastrocola, D., \& Pittia, P. (2015). Physical and structural properties of extra-virgin olive oil based mayonnaise. $L W T$ Food Science and Technology, 62(1), 764-770. https://doi.org/10.1016/j.lwt.2014.09. 065.

Dordevic, V., Balanc, B., Belscak-cvitanovic, A., Levic, S., Trifkovic, K., Kalusevic, A., ... Nedovic, V. (2015). Trends in encapsulation technologies for delivery of food bioactive compounds. Food Engineering, 7, 452-490. https://doi.org/10.1007/ s12393-014-9106-7.

Freiberger, E. B., Kaufmann, K. C., Bona, E., Hermes de Araújo, P. H., Sayer, C., Leimann, F. V., \& Gonçalves, O. H. (2015). Encapsulation of roasted coffee oil in biocompatible nanoparticles. LWT - Food Science and Technology, 64(1), 381-389. https://doi.org/ 10.1016/j.lwt.2015.05.039.

Fuchs, R. H. B., Ribeiro, R. P., Matsushita, M., Tanamati, A. A. C., Bona, E., \& de Souza, A. H. P. (2013). Enhancement of the nutritional status of Nile tilapia (Oreochromis niloticus) croquettes by adding flaxseed flour. LWT - Food Science and Technology, 54(2), 440-446. https://doi.org/10.1016/j.lwt.2013.07.004.

Gardette, J. L., \& Baba, M. (2013). FTIR and DSC studies of the thermal and photochemical stability of Balanites aegyptiaca oil (Toogga oil). Chemistry and Physics of Lipids, 170-171, 1-7. https://doi.org/10.1016/j.chemphyslip.2013.02.008.

González, A., Martínez, M. L., Paredes, A. J., León, A. E., \& Ribotta, P. D. (2016). Study of the preparation process and variation of wall components in chia (Salvia hispanica L.) oil microencapsulation. Powder Technology, 301, 868-875. https://doi.org/10.1016/ j.powtec.2016.07.026.

Grampone, M. A., Irigaray, B., Rodríguez, D., \& Sammán, N. (2013). Assessing the oxidative stability of commercial chia oil. Journal of Food Science and Engineering, 3, 349-356.

Guimarães-Inácio, A., Francisco, C. R. L., Rojas, V. M., Leone Valderrama, R. de S. P., Bona, E., ... Gonçalves, O. H. (2018). Evaluation of the oxidative stability of chia oilloaded microparticles by thermal, spectroscopic and chemometric methods. $L W T$ Food Science and Technology, 87, 498-506. https://doi.org/10.1016/j.lwt.2017.09. 031.

Instituto Adolfo Lutz. (2008). Métodos Físico-Químicos para Análise de Alimentos. Métodos Físico-Químicos para Análise de Alimentos.

ISO 8587. (2006). Sensory analysis — Methodology — Ranking. International Standard ISO 8587.

Ixtaina, V. Y., Mattea, F., Cardarelli, D. A., Mattea, M. A., Nolasco, S. M., \& Tomas, M. C. (2011). Supercritical carbon dioxide extraction and characterization of Argentinean chia seed oil. Journal of the American Oil Chemists Society, 88(2), 289-298. https://doi. org/10.1007/s11746-010-1670-2.

Jiao, J., Li, Z. G., Gai, Q. Y., Li, X. J., Wei, F. Y., Fu, Y. J., \& Ma, W. (2014). Microwaveassisted aqueous enzymatic extraction of oil from pumpkin seeds and evaluation of its physicochemical properties, fatty acid compositions and antioxidant activities. Food Chemistry, 147, 17-24. https://doi.org/10.1016/j.foodchem. 2013.09.079.

Kaijser, A., Dutta, P., \& Savage, G. (2000). Oxidative stability and lipid composition of macadamia nuts grown in New Zealand. Food Chemistry, 71(1), 67-70. https://doi org/10.1016/S0308-8146(00)00132-1.
Litwinienko, G., \& Kasprzycka-Guttman, T. (1998). A DSC study on thermoxidation kinetics of mustard oil. Thermochimica Acta, 319(1-2), 185-191. https://doi.org/10. 1016/S0040-6031(98)00410-9.

Liu, H., Xu, X. M., \& Guo, S. D. (2007). Rheological, texture and sensory properties of lowfat mayonnaise with different fat mimetics. LWT - Food Science and Technology, 40(6), 946-954. https://doi.org/10.1016/j.lwt.2006.11.007.

Mansara, P. P., Deshpande, R. A., Vaidya, M. M., \& Kaul-Ghanekar, R. (2015). Differential ratios of omega fatty acids (AA/EPA + DHA) modulate growth, lipid peroxidation and expression of tumor regulatory MARBPs in breast cancer cell lines MCF7 and MDAMB-231. PLoS One, 10(9), 1-22. https://doi.org/10.1371/journal.pone.0136542.

Micić, D. M., Ostojić, S. B., Simonović, M. B., Krstić, G., Pezo, L. L., \& Simonović, B. R. (2015). Kinetics of blackberry and raspberry seed oils oxidation by DSC. Thermochimica Acta, 601, 39-44. https://doi.org/10.1016/j.tca.2014.12.018.

Miele, N. A., Di Monaco, R., Cavella, S., \& Masi, P. (2010). Effect of meal accompaniments on the acceptability of a walnut oil-enriched mayonnaise with and without a health claim. Food Quality and Preference, 21(5), 470-477. https://doi.org/10.1016/j. foodqual.2010.01.001.

Ostrowska-Ligeza, E., Bekas, W., Kowalska, D., Lobacz, M., Wroniak, M., \& Kowalski, B. (2010). Kinetics of commercial olive oil oxidation: Dynamic differential scanning calorimetry and Rancimat studies. European Journal of Lipid Science and Technology, 112(2), 268-274. https://doi.org/10.1002/ejlt.200900064.

Ozawa, T. (1970). Kinetic analysis of derivate curves in thermal analysis. Journal of Thermal Analyses, 2, 301-324.

Procida, G., Stancher, B., Cateni, F., \& Zacchigna, M. (2013). Chemical composition and functional characterisation of commercial pumpkin seed oil. Journal of the Science of Food and Agriculture, 93(5), 1035-1041. https://doi.org/10.1002/jsfa.5843.

Rahmati, K., Tehrani, M. M., \& Daneshvar, K. (2014). Soy milk as an emulsifier in mayonnaise: Physico-chemical, stability and sensory evaluation. Food Science Technology, 51, 3341-3347. https://doi.org/10.1007/s13197-012-0806-9.

Raudsepp, P., Brüggemann, D. A., Lenferink, A., Otto, C., \& Andersen, M. L. (2014). Oxidative stabilization of mixed mayonnaises made with linseed oil and saturated medium-chain triglyceride oil. Food Chemistry, 152, 378-385. https://doi.org/10. 1016/j.foodchem.2013.11.141.

Sagiri, S. S., Singh, V. K., Pal, K., Banerjee, I., \& Basak, P. (2015). Stearic acid based oleogels: A study on the molecular, thermal and mechanical properties. Materials Science and Engineering C, 48, 688-699. https://doi.org/10.1016/j.msec. 2014.12. 018.

Siano, F., Straccia, M. C., Paolucci, M., Fasulo, G., Boscaino, F., \& Volpe, M. G. (2016). Physico-chemical properties and fatty acid composition of pomegranate, cherry and pumpkin seed oils. Journal of the Science of Food and Agriculture, 96(5), 1730-1735. https://doi.org/10.1002/jsfa.7279.

Silva, V. D., Conceição, J. N., Oliveira, I. P., Lescano, C. H., Muzzi, R. M., Filho, O. P. S., .. Caires, A. R. L. (2015). Oxidative stability of Baru (Dipteryx alata Vogel) oil monitored by fluorescence and absorption spectroscopy. Journal of Spectroscopy, 2015. https://doi.org/10.1155/2015/803705.

Simopoulos, A. P. (2008). The omega-6/omega-3 fatty acid ratio, genetic variation, and cardiovascular disease. Asia Pacific Journal of Clinical Nutrition, 17(S1), 131-134.

Souza, M. F., Sanchez, J. L., Valderrama, P., Bona, E., Tanamati, A. A. C., Leimann, F. V., \& Gonçalves, O. H. (2015). Fatty acids profile of chia oil-loaded lipid microparticles. Brazilian Journal of Chemical Engineering, 1-22.

Sun, C., Liu, R., Liang, B., Wu, T., Sui, W., \& Zhang, M. (2018). Microparticulated whey protein-pectin complex: A texture-controllable gel for low-fat mayonnaise. Food Research International, 108, 151-160. https://doi.org/10.1016/j.foodres. 2018.01. 036.

Timilsena, Y. P., Vongsvivut, J., Adhikari, R., \& Adhikari, B. (2017). Physicochemical and thermal characteristics of Australian chia seed oil. Food Chemistry, 228, 394-402. https://doi.org/10.1016/j.foodchem.2017.02.021.

Ullah, R., Nadeem, M., Ayaz, M., Imran, M., \& Tayyab, M. (2016). Fractionation of chia oil for enrichment of omega 3 and 6 fatty acids and oxidative stability of fractions. Food Science and Biotechnology, 25(1), 41-47. https://doi.org/10.1007/s10068-0160006-x.

Wong, P. C. H., Heng, P. W. S., \& Chan, L. W. (2015). Determination of solid state characteristics of spray-congealed ibuprofen solid lipid microparticles and their impact on sustaining drug release. Molecular Pharmaceutics, 12(5), 1592-1604. https:// doi.org/10.1021/acs.molpharmaceut.5b00015.

Wood, J. D., Richardson, R. I., Nute, G. R., Fisher, A. V., Campo, M. M., Kasapidou, E., .. Enser, M. (2004). Effects of fatty acids on meat quality: A review. Meat Science, 66(1), 21-32. https://doi.org/10.1016/S0309-1740(03)00022-6. 